CONGRESS COVERAGE

\title{
Obese Children have a Quadrupled Risk of Becoming Hypertensive Adults in Comparison to Children with Normal Weight
}

\author{
Emmanuel S. Ganotakis ${ }^{1}$, Aikaterini Papagianni ${ }^{2}$ and Vasilios G. Athyros ${ }^{3, *}$ \\ ${ }^{I}$ Department of Internal Medicine, Heraklion Medical School, University Hospital of Heraklion, Crete, Greece; \\ ${ }^{2}$ Department of Nephrology, Medical School, Aristotle University of Thessaloniki, Hippokration Hospital, Thessaloniki, \\ Greece, ${ }^{3}$ Department of Internal Medicine, Medical School, Aristotle University of Thessaloniki, Hippokration Hospital, \\ Thessaloniki, Greece
}

Keywords: Childhood, obesity, overweight, adulthood, arterial hypertension, treatment options.

A few days ago (Sept 12, 2013) the results of a large prospective study that included 1,117 healthy children who were followed up for 27 years were presented in the American Heart Association (AHA) High Blood Pressure Research Scientific Sessions in New Orleans [1]. The aim was to record the development of obesity in childhood and to investigate the incidence of arterial hypertension (HTN) in adults that were obese or overweight children [1]. The original cohort was established in 1986, and consisted of 1,117 healthy children (47\% male), recruited from schools in Indianapolis, Indiana, USA (mean age 12 years). During follow-up, blood pressure (BP), height, and weight were measured twice a year. Body mass index (BMI) was calculated from height and weight; weight status was determined by age and sexadjusted BMI percentile values (BMI \%). Subjects were classified as normal weight, overweight (BMI $\% \geq 85 \%$ and $<95 \%$ ), or obese (BMI $\% \geq 95 \%$ ) of BMI distribution of the entire cohort [1]. The above revealed that $765(68 \%)$ had normal weight, $176(16 \%)$ were overweight, and $176(16 \%)$ were obese [1]. The rate of adult HTN was higher for those classified as overweight or obese as children (14\% and $26 \%$ respectively, $\mathrm{p}=<0.0001)$. Children classified as overweight or obese had double and quadruple the risk of having HTN in adulthood, respectively, as compared to normal weight children [odds ratio $(\mathrm{OR})=2.2 ; 95 \%$ confidence interval $(\mathrm{CI})=1.3$ to $3.6, \mathrm{OR}=4.4 ; 95 \% \mathrm{CI}=2.8$ to 6.9 , respectively] [1]. It has also been shown that children who had one or more high BP readings are 3 times more likely to develop HTN as adults. Using the same pool of Indianapolis kids, researchers found that the rate of high BP during adulthood was $8.6 \%$ for children who didn't have a high BP reading when they were young. That rate jumped to $18 \%$ for adults who had at least 1 high reading as a kid, and 35\% for adults who had 2 or more high readings as children [1]. This study highlights the need for pediatricians to regularly check BP

\footnotetext{
*Address correspondence to this author at the Department of Internal Medicine, Medical School, Aristotle University of Thessaloniki, Hippokration Hospital, 15 Marmara St, Thessaloniki, 55132, Greece; Tel: +30 2310 892606; Fax: +30 2310835955 ;

Emails: athyros@med.auth.gr and vathyros@gmail.com
}

and weight. Authors conclude that the degree of adiposity in childhood significantly impacts the risk for HTN in adulthood; childhood obesity is associated with a quadrupled risk of adult HTN [1].

All the above have significant implications and suggest that urgent steps should be taken for early prevention of childhood obesity. This is because, besides HTN, other health problems, such as renal injury, which further promote HTN within a vicious cycle [2], and finally vascular damage early in life, which leads to cardiovascular disease (CVD) [2] are also related to childhood obesity.

It has been shown that there is substantial increase in the prevalence of end-stage renal disease (ESRD) over the last three decades, paralleling the increasing prevalence of obesity and insulin resistance (IR), including the pediatric population [2]. Overweight, obesity and the metabolic syndrome (MetS), which frequently coexist, contribute substantially to CVD and ESRD [2]. A higher BMI, the presence of type 2 diabetes (T2DM), HTN, and IR have recently emerged as strong independent risk factors for chronic kidney disease (CKD) and ESRD [2]. It should be noted that the long-term CVD impact of obesity, although expressed in adulthood, has its origin in childhood [2,3]. Childhood obesity is fast becoming a worldwide epidemic, with its prevalence tripled in the last three decades [2]. At present, approximately $20 \%$ of children and adolescents in Western countries are overweight or obese; this prevalence has reached $10 \%$ in developing countries [2]. By 2020 the prevalence of childhood overweight and obesity is estimated that will be $>35 \%$ in Europe and $>45 \%$ in America; even in Southeast Asia, the average prevalence will reach $20 \%$ [3].

Obesity, MetS, and IR lead, among others, increase angiotensin II levels, BP, intraglomerular pressure, and proteinuria, raise the production of intrarenal inflammatory cytokines/growth factors, and finally induce apoptosis. These have a deleterious effect on CV system and induce CKD in adulthood [2,3]. All the above are alarming and underline how obesity is a real threat not only for adults, but also for children and adolescents [4], since metabolic as well as CVD 
complications of obesity may already be present at a very young age [5].

Vascular function abnormalities precede the development of vascular anatomical pathology in adults [5]. Reduced endothelial function and arterial compliance and increased inflammatory markers, are detectable in obese and diabetics, even from childhood, prior to the appearance of anatomical abnormalities [5]. Early changes in vascular risk factors such as obesity, hyperlipidaemia, HTN, and dysglycaemia promote initial endothelial dysfunction and arterial stiffness. Inflammation and continued presence of these risk factors leads subsequently to atherosclerosis with altered vascular structure and function as well as to arteriosclerosis with increased stiffness of the large vessels [5]. These, along with $\mathrm{CKD}$, are major CVD risk factors.

A few days ago (Sept 9, 2013) an AHA Scientific Statement on Severe Obesity in Children and Adolescents was released and it was published in the Circulation Journal [6]. This Statement reports that severe obesity afflicts between $4 \%$ and $6 \%$ of all youth in the United States, with an increasing prevalence [6]. In regard to interventions the results in obese children are disappointing. Behavioural interventions have been studied in children and adolescents aged 4-18 years, while adjunctive pharmacological interventions have been studied only in severely obese adolescents $[7,8]$. Lifestyle modification, including exercise and hypocaloric diet showed only modest improvement in BMI status, but participants have generally remained obese and often regained weight after the end of the treatment programs [6-8]. Behavioural interventions in schools or specialty health care settings can result in small to moderate short-term improvements, which varies by treatment intensity $[7,8]$. These, however induced some beneficial effects on weight compared with no or minimal treatment [7,8]. Authors of the Indianapolis Study report that they have good evidence that family treatments for childhood obesity can improve BMI and can improve BP in adolescents and adults. Strategies involving the family can be helpful in reducing childhood

Received: September 25, 2013

Accepted: September 25, 2013 obesity. It's important to consider the family as a unit and try to reduce obesity in all the members of the family [1].

\section{CONFLICT OF INTEREST}

The author(s) confirm that this article content has no conflicts of interest.

\section{ACKNOWLEDGEMENT}

Declared none.

\section{REFERENCES}

[1] Watson SE, Hannon TS, Eckert GJ, Pratt JH, Rosenman M, Tu W. Adult Hypertension Risk is More than Quadrupled in Obese Children. AHA, High Blood Pressure Research 2013 Scientific Sessions, New Orleans, USA, Abstract 036. http://my.americanheart.org/idc/groups/ahamahpublic/@wcm/@sop/@scon/_documents/downloadable/ ucm_455971.pdf

[2] Saviño A, Pelliccia P, Chiarelli F, Mohn A. Obesity-related renal injury in childhood. Horm Res Paediatr 2010; 73: 303-11.

[3] Wang Y, Chen X, Klag MJ, Caballero B. Epidemic of childhood obesity: implications for kidney disease. Adv Chronic Kidney Dis 2006; 13: 336-51.

[4] Chiarelli F, Marcovecchio ML. Insulin resistance and obesity in childhood. Eur J Endocrinol 2008; 159: S67-S74.

[5] Short KR, Blackett PR, Gardner AW, Copeland KC. Vascular health in children and adolescents: effects of obesity and diabetes. Vasc Health Risk Manag 2009; 5: 973-90.

[6] Kelly AS, Barlow SE, Rao G, et al. on behalf of the American Heart Association Atherosclerosis, Hypertension, and Obesity in the Young Committee of the Council on Cardiovascular Disease in the Young, Council on Nutrition, Physical Activity and Metabolism, and Council on Clinical Cardiology. Severe Obesity in Children and Adolescents: Identification, Associated Health Risks, and Treatment Approaches: A Scientific Statement from the American Heart Association. Circulation 2013 Sep 9. [Epub ahead of print]

[7] Whitlock EP, O'Connor EA, Williams SB, Beil TL, Lutz KW. Effectiveness of Weight Management Programs in Children and Adolescents. Evidence Reports/Technology Assessments, No. 170. Rockville (MD): Agency for Healthcare Research and Quality (US); $\quad$ September 2008. http://www.ncbi.nlm.nih.gov/books/NBK36416/pdf/ TOC.pdf

[8] Whitlock E, O'Connor E, Williams S, Beil T, Lutz K. Effectiveness of weight management programs in children and adolescents. Evid Rep Technol Assess (Full Rep) 2008; 170: 1-308.

(C) Ganotakis et al.; Licensee Bentham Open.

This is an open access article licensed under the terms of the Creative Commons Attribution Non-Commercial License (http://creativecommons.org/licenses/by-nc/3.0/) which permits unrestricted, non-commercial use, distribution and reproduction in any medium, provided the work is properly cited. 